\title{
Summary of: Patients' attitudes towards screening for diabetes and other medical conditions in the dental setting
}

\section{FULL PAPER DETAILS}

${ }^{1}$ Centre for Medical Statistics and Bioinformatics, Plymouth University Peninsula Schools of Medicine and Dentistry, Plymouth; ${ }^{2}$ Plymouth University Peninsula Schools of Medicine and Dentistry, Plymouth; ${ }^{3 R e s e a r c h ~ D e s i g n ~ S e r v i c e ~ S o u t h ~ W e s t, ~ I T T C ~}$ Building, Tamar Science Park, Plymouth ${ }^{*}$ Correspondence to: Siobhan Creanor Email:siobhan.creanor@plymouth.ac.uk; Tel: 01752764434

Refereed Paper

Accepted 26 September 2013

DOI: 10.1038/sj.bdj.2013.1247

British Dental Journal 2014; 216: E2

\author{
S. Creanor, ${ }^{* 1}$ B. A. Millward, ${ }_{1}^{2}$ A. Demaine, ${ }_{1}^{2}$ L. Price, $_{1}^{3}$ W. Smith, ${ }_{1}^{2}$ \\ N. Brown ${ }^{2}$ and S. L. Creanor ${ }^{2}$
}

\begin{abstract}
Aim To determine the attitudes of patients attending routine appointments at primary care dental clinics and general dental practices towards the possibility of chair-side screening for medical conditions, including diabetes, in the dental setting. Methods A brief, anonymous, self-administered questionnaire distributed to adult patients ( $\geq 18$ years) attending 2 primary care dental clinics and 16 general dental practices in South-West England. Results One hundred and ninetyseven completed questionnaires were received from patients at primary care dental clinics and 429 from general dental practice patients. Overall, 87\% of respondents thought that it was important or very important that dentists screened patients for medical conditions such as diabetes; $79 \%$ were very willing to let a dental team member carry out screening. The majority indicated willingness to be screened for various medical conditions during a visit to the dentist, with significantly higher proportions of respondents in the primary care clinics indicating willingness (hypertension: 83\% vs 74\%; heart disease: $77 \%$ vs 66\%; diabetes $82 \%$ vs $72 \%$ [all $p<0.02$ ]). Nearly two thirds of primary care clinic respondents and over half of general practice patients indicated that they would be willing to discuss test results with the dental team. Overall, 61\% had never knowingly been screened or tested for diabetes; $20 \%$ reported that they had been tested within the previous 12 months. Conclusion The majority of respondents supported the concept of medical screening in a dental setting and were willing both to have screening tests and discuss their results with the dental team. Patient acceptance is paramount for successful implementation of such screening programmes.
\end{abstract}

\section{EDITOR'S SUMMARY}

Across the world, 347 million people have diabetes; with 3.1 million living in the UK. The cost of diabetes to the NHS is £14 billion pounds a year; that's over $£ 1.5$ million an hour. ${ }^{1}$ It even takes £300,000-a-weekfootballer Gareth Bale 36 whole days to earn that much. It equates to over $10 \%$ of the NHS budget. ${ }^{1}$

Diabetes type 2 is essentially a preventable disease, just like dental caries. Yet about $85 \%$ of the $£ 14$ billion spent on treating diabetes goes on type 2 diabetes.

Putting aside the colossal cost of medical treatment and care for diabetes sufferers, the 'social' costs alone are estimated to come to another $£ 15.5$ billion each year; that's about $£ 29,500$ a minute (around 17 hours of 'Gareth Bale time' to pay for one minute of the costs incurred by this). The social costs encompass all outlays due to absenteeism, early retirement and social benefits attributed to diabetes. ${ }^{1}$

It's not just about the financial costs either is it? (Though this does make it eas- ier to understand the scale of the problem.) It's about the patients: their quality of life and how much better it could be if we stem the ever-increasing incidence of the disease. If we don't? The number of people with diabetes in the UK is currently predicted to increase to 4.6 million $(9.5 \%$ of the population) by 2030 .

As the authors of this study indicate, the diabetes problem is exacerbated because about 25\% of cases are unrecognised. If those at risk of diabetes are identified early then the onset of the condition can be delayed or even prevented. As over $60 \%$ of UK adults regularly attend a dentist, it would seem an opportune place to reach those at high risk of diabetes. There is some debate amongst dentists regarding general health screening of this kind in the dental practice; ${ }^{2,3}$ however, this study investigates whether or not dental patients themselves would support this type of screening.

The majority of respondents in this study are willing to accept medical screening at the dentist. However, in a recent $B D J$ study ${ }^{4}$ investigating the oral health awareness of adult patients nearly two thirds of respondents indicated their unwillingness to pay for screening if offered by dentists. Perhaps Gareth Bale could lend a hand?

The full paper can be accessed from the $B D J$ website (www.bdj.co.uk), under 'Research' in the table of contents for Volume 216 issue 1.

\section{Ruth Doherty Managing Editor}

1. 2010 information for UK. Online information available at www.diabetes.co.uk (accessed December 2013).

2. Creanor S, Millward A, Coelho A, Creanor S. Worrying attitudes. Br Dent J 2013; 215: 202.

3. Sjögren P. Ethics of health screening. Br Dent J 2013: 213: 434.

4. Bowyer V, Sutcliffe P, Ireland R et al. Oral health awareness in adult patients with diabetes: a questionnaire study. Br Dent J 2011; 211: E12.

DOI: 10.1038/sj.bdj.2013.1245 


\section{TO ACCESS THE BDJ WEBSITE TO READ THE FULL PAPER}

- BDA Members should go to www.bda.org.

- Click the 'login' button on the right-hand side and enter your BDA login details.

- Once you have logged in click the 'BDJ' tab to transfer to the BDJ website with full access.

IF YOUR LOGIN DETAILS DO NOT WORK:

- Get a password reminder: go to www.bda.org, click the login button on the right-hand side and then click the forgotten password link.

- Use a recommended browser: we recommend Microsoft Internet Explorer or Mozilla Firefox.

- Ensure that the security settings on your browser are set to recommended levels.

IF YOU HAVE NOT YET SIGNED UP TO USE THE BDA WEBSITE:

- Go to www.bda.org/getstarted for information on how to start using the BDA website.

\section{COMMENTARY}

This is a potentially useful study in an area that is becoming increasingly important in light of the growing number of people developing diabetes. Previous work in the field of diabetes has demonstrated the willingness of the general public to be screened for diabetes and it is encouraging to see how positive patients feel about using a dental setting to screen for general as well as oral health conditions. This paper raises a number of issues that need addressing, however.

The paper addresses the possibility of screening all dental patients for diabetes and yet the UK National screening policy guidelines on screening for diabetes clearly state that systematic population screening is not recommended and that risk-based screening should be undertaken; this needs to be clarified in the study. The second area that we would highlight is that screening is not the same as diagnosis. This needs to be explicit in patient literature and in communication with patients about the screening programme as they may not always be aware of the difference between the two. In addition, it would be necessary to be explicit about the type of screening procedure used in the clinic as there are different methods of screening available, some of which are more invasive/accurate than others.

Respondents in this study stated a preference for discussing the screening results initially with dental staff before referral to the general practice team. It is therefore essential that the dental teams involved in such screening are confident in explaining the implications of the screening results and have the communication skills to do this in a way that will encourage the patient to seek a diagnostic test without causing undue fear. Psychological research has clearly demonstrated that increasing fear in the absence of increasing the ability to cope with the fear is unhelpful to the patient.

Finally, there is only very basic demographic information presented in this paper and it would be useful to have more details about the background of the respondents. Research on deprived populations suggests that the sector of the population most at risk of developing diabetes are the least likely group to visit dentists routinely and are more likely to visit symptomatically. This makes the targeting of screening even more important.

Screening in dental settings is potentially an important step in the fight to control the rise in the number of people being diagnosed with diabetes. It is essential, however, that if such screening is undertaken it is targeted at those most in need, and the results and their implications are clearly and effectively communicated.

Sasha Scambler and Koula Asimakopoulou Unit of Social and Behavioural Sciences, King's College London Dental Institute.

\section{AUTHOR QUESTIONS AND ANSWERS}

1. Why did you undertake this research?

There has been interest in screening for medical conditions in the dental setting for many decades, with studies going back to the 1960s. With the alarming rise in the prevalence of diabetes across the world, the possibility of screening for diabetes in the dental setting has recently received increasing interest overseas, particularly in the USA. Our research group was already discussing the possibility of exploring such a screening process when NICE published guidance on risk-assessment for Type 2 diabetes (T2DM) in 2012. This guidance suggests that dental surgeries should be offering risk-assessment for T2DM but currently there is no UK evidence to support this approach. We undertook this survey to gauge UK dental patients' attitudes towards screening for medical conditions as we felt that this was a fundamental first step - successful implementation of any offer of screening firstly requires the support of potential users of the service.

2. What would you like to do next in this area to follow on from this work?

With an estimated 850,000 cases of undiagnosed diabetes, we need to explore new opportunities to identify these people. In the UK over half of adults regularly attend their dentist and so dental professionals are well-placed to help identify people at high-risk of diabetes. We are already exploring opportunities for further research in this area. In particular, we think it is important that there is good quality evidence to show that risk-assessment for T2DM in the UK dental setting is feasible and effective as well as costeffective. To encourage the dental profession to participate and apply the NICE guidance in their day-to-day practice, the possible barriers to implementation also need to be explored and overcome. 